cell presentation and mechanical cell recognition. The routine cytologist is left in some awe at the ingeniousness and vigour with which the problem of automated screening is tackled in such a variety of ways but, equally, the reader cannot but be discouraged by the apalling complexity of the problem, in some measure due to the overlap of the characteristics of normal and abnormal cells. Indeed, those in charge of routine screening departments will receive no comfort from these proceedings. The day that a mechanical device will be able to relieve the drudgery and monotony of the cytological technician by separating a high proportion of normal smears from those which require individual assessment by the human eye is as far off as ever. Wied of Chicago (p. 47) dashes any hopes one may have entertained: ' . . there is no currently existing machine, there is no machine in preparation, there is no machine in production at this time and there will be no economically feasible machine in the foreseeable future which will obviate the need for trained cytotechnologists and cytopathologists. We would be better to face reality than to indulge in imaginary daydreams of non-existing machines.'

\section{Aids to Postgraduate Medicine}

Edited by J. L. Burton. Pp. 136. Edinburgh and London: E. \& S. Livingstone, 1970. £1.

The Author, a Senior Registrar in the University Department of Dermatology, Newcastle-upon-Tyne, states that this little book is primarily intended to provide aid to revision for candidates taking the Membership examination in the United Kingdom.

A great number of facts are listed under various headings, some of which are controversial, and a well informed candidate will have to analyse them carefully before answering examination questions. The book does not encourage any rational thinking and may give a wrong impression, especially to overseas candidates, that one can obtain the M.R.C P. by memorizing certain facts. If such an impression is created many candidates would fail and, therefore, I for one, would not recommend it to my junior colleagues. However, it may prove useful to a clinician who wishes to know a list of possibilities and facts at a glance.

The book has twelve chapters and a useful bibliography of books and journals, from which most of the listed facts are derived, appears at the end. There is no index but instead the author has wisely provided three blank pages for additional information to be added by an individual if he needs it.

\section{Liver Disease}

By A. Paton. Pp. 185, illustrated. William Heinemann Medical Books, London, 1969. £1 10s.

This book grew out of a series of lectures given to various Postgraduates, not necessarily those specialising in Medicine.
It contains excellent accounts of the management of obstructive jaundice and of the relationship between chronic alcoholism and liver damage. The sections on portal hypertension, ascites and hepatic coma are also sound. There are, however, some inconsistences as for instance, in discussing the frequency of severe jaundice in metastatic hepatic disease and its relation to enlarged glands in the porta hepatis (discussed on pages 50 and 106).

Adequate details of treatment regimes are not always given. The use of antifibrinolytic agents and of heparin in the treatment of increased fibrinolysis and intravascular coagulation in cirrhosis is considered in a few sentences with no mention of the care needed in their use. There are also some errors including one in the first sentence of the book where the liver is said to be one-fifth of the body weight. Some of the views expressed in different sections are not widely accepted, e.g. that narcotics such as opium and marijhuana may cause cirrhosis, that there may be at least three distinct viruses in infectious hepatitis and that renal failure is no commoner in patients operated on for obstructive jaundice than in other types of major surgery.

There may indeed be a gap between the sections on liver disease in undergraduate text books and the larger monographs on liver disease, but it would seem a pity to separate liver disease from Gastroenterology at this stage of Postgraduate training.

\section{Virus Diseases of the Liver}

By A. J. Zuckermann. Pp. 158, illustrated. London: Butterworths, 1970. $£ 46 \mathrm{~s}$.

It is a pleasure to write a review on "Virus Diseases of the Liver' for this book brings together much information and literature on an important subject that has previously been scattered through many Journals. The text is clear, the illustrations superb and the net effect is to stimulate interest even more in this rapidly advancing field. Particularly valuable are the chapters describing infections of the liver by viruses other than the hepatitis virus: cytomegalovirus, herpes virus, adenovirus, rubella virus and the recent work concerning E.B. virus in infectious mononucleosis are all well covered. There is a fascinating account of events leading to the outbreak of Green Monkey Disease which in 1967 affected monkey handlers and laboratory workers in three European cities-Marburg, Frankfurt and Belgrade, together with the world wide studies on the possible agent involved which followed this outbreak. The techniques for tissue culture of embryo and adult human liver cells developed in the author's laboratories will be of interest to those concerned in this field. There is also a complete account of all the agents which at one time or another have been incriminated in infectious hepatitis leading up to the present story of Australia Antigen. The general reader as well as those interested in the liver and in viruses will find much of interest. 